\title{
Non-Contact Measurement of Blade Vibration in an Axial Compressor
}

\author{
Radoslaw Przysowa ${ }^{1, *(D)}$ and Peter Russhard ${ }^{2}$ (D) \\ 1 Instytut Techniczny Wojsk Lotniczych (ITWL), ul. Księcia Bolesława 6, 01-494 Warszawa, Poland \\ 2 EMTD Ltd., 22 Woods Meadow, Derby DE72 3UX, UK; peter.russhard@emtd-measurement.com \\ * Correspondence: radoslaw.przysowa@itwl.pl
}

Received: 24 November 2019; Accepted: 19 December 2019; Published: 21 December 2019

\begin{abstract}
Complex blade responses such as a rotating stall or simultaneous resonances are common in modern engines and their observation can be a challenge even for state-of-the-art tip-timing systems and trained operators. This paper analyses forced vibrations of axial compressor blades, measured during the bench tests of the SO-3 turbojet. In relation to earlier studies conducted in Poland with a small number of sensors, a multichannel tip-timing system let us observe simultaneous responses or higher-order modes. To find possible symptoms of a failure, blade responses in a healthy and unhealthy engine configuration with an inlet blocker were studied. The used analysis methods covered all-blade spectrum and the circumferential fitting of blade deflections to the harmonic oscillator model. The Pearson coefficient of correlation between the measured and predicted tip deflection is calculated to evaluate fitting results. It helps to avoid common operator mistakes and misinterpreting the results. The proposed modal solver can track the vibration frequency and adjust the engine order on the fly. That way, synchronous and asynchronous vibrations are observed and analysed together with an extended variant of least squares. This approach saves a lot of work related to configuring the conventional tip-timing solver.
\end{abstract}

Keywords: blade vibration; blade tip-timing; rotating stall; axial compressor; blade health monitoring; least squares; bladed disc dynamics

\section{Introduction}

Non-contact blade vibration measurement, known as blade tip-timing (BTT) or Non-Intrusive Stress Measurement System (NSMS), is a technique for determining dynamic blade stresses to ensure the structural integrity of bladed disks in jet engines and stationary turbines [1,2]. It can be used in axial or radial compressors [3] and unshrouded or shrouded turbines [4]. The method uses several sensors mounted circumferentially to precisely determine temporary positions of each blade tip in every rotation [5]. Model-based data processing is necessary to determine the real amplitude and vibration [6,7]. BTT solutions used by industry are still based on algorithms established at the end of the 20th century. Most vibration surveys rely upon traversing each of the resonances. Analysing responses at a constant speed is more difficult to achieve.

In most applications, undersampled tip deflection signals are generally processed by the two groups of methods: (1) Fourier spectral analysis, e.g., all-blade spectrum, (2) least squares fitting (LSF). Fourier transform methods compromise time and frequency resolution and involve significant post-processing to reconstruct the real spectrum. They are now used primarily to identify the presence of non-integral vibration and to determine nominal frequency and nodal diameter. This data seeds least squares fitting [8]. LSF is now the main method used in most of BTT systems to extract the real amplitude and phase for successive revolutions. It can be used either circumferentially to fit the blade mode or axially to fit the mode shape - each has a different strategy for conversion to stress [9]. The 
models for this can be simplistic sine fitting [10] or more complex ones derived from the finite element method (FEM) during the calibration and validation process used with BTT.

Alternative methods introduced in the previous decade such as auto-regressive [11], spectral estimation using nonuniform sampling [12], or full-signal analysis using many points per blade pass [13], were too complex or not efficient enough to leave the labs and be widely used by the community. These alternative methods provide little additional capability to the BTT technology but are often revisited by researchers [14-16] in the hope of finding methods for in-service blade health monitoring (BHM), where the blade sets are already well understood.

A significant number of papers, introducing new BTT models and algorithms such as a new two-parameter plot method [17], convolutional neural networks [18], aliasing reduction [19,20], sparse representation, and compressed sensing [21], were published recently, but they can be applied in real life to a limited extent. Several newly introduced algorithms work well only with simulated or rig acquired data, usually with a single response of the first mode. Further efforts are needed to make them more mature to better deal with noise and weak or more complex responses.

Validation against simulation is not accepted for certification of engines [22]. BTT technique was already used in component certification tests, where the evidence to calculate a meaningful value of stress was produced [23]. However, a documented validation of the measurement system and ability to estimate uncertainty are still missing in many BTT applications.

This paper presents robust and efficient methodology of processing tip-timing data which produces vibration results of known and controlled uncertainty. It is demonstrated on two datasets acquired in a realistic test-cell environment.

First, stack pattern is calculated to check alignment, validate measurement data, and avoid misinterpreting it, especially when strong low-order excitation force is present. Then, an extended method of least squares is used to analyse coinciding integral and non-integral blade vibrations together. The Pearson coefficient of correlation between the measured and predicted tip deflection is calculated to evaluate fitting results.

Finally, to study interaction between the rotating stall and integral resonance, a new modal solver is used, which can track the modal frequency and adjust the engine order on the fly, producing results similar to strain gauges. Measurement uncertainty is calculated for any point on the tracked order response to assess the overall results.

\section{Materials and Methods}

This work analyses forced vibrations of axial compressor blades, measured with tip timing system during the bench tests of the SO-3 turbojet. SO-3 is a first generation single-spool engine with the seven-stage axial compressor and no variable stator vanes. It rotates anticlockwise (looking from aft forward) with the maximum speed 15,600 rpm. There are 28 blades in the first stage with dovetail roots (Figure 1), made of 18H2N4MA steel and painted yellow for protection against corrosion. The stage is subsonic, preceded by three struts and 44 constant inlet guide vanes (IGV), and followed by 34 downstream vanes.
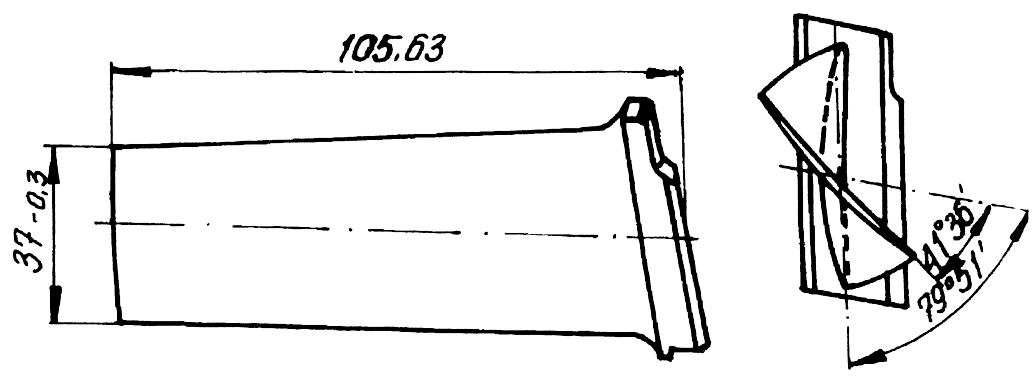

Figure 1. Geometry of the first-stage blade. 
The conducted engine tests were aimed to characterise blade vibrations i.e., identify existing responses, especially high-order ones. This is often necessary when investigating blade failure in legacy compressors or turbines, when design data are not available or not reliable.

The purpose of fitting a felt blocker to the inlet (Figure 2) was not to force any particular order, but to excite as many responses as possible. It significantly increased blade vibration [24] and simulated icing, a bird, or another foreign object ingested and stuck into the inlet guide vanes. Its role was to excite a wide array of resonances, which are normally difficult to measure. Previous research showed [25-27] that operation with a foreign object in the inlet results in M1EO2 resonant vibrations exceeding critical stresses and can lead to their fatigue cracking even after several minutes.

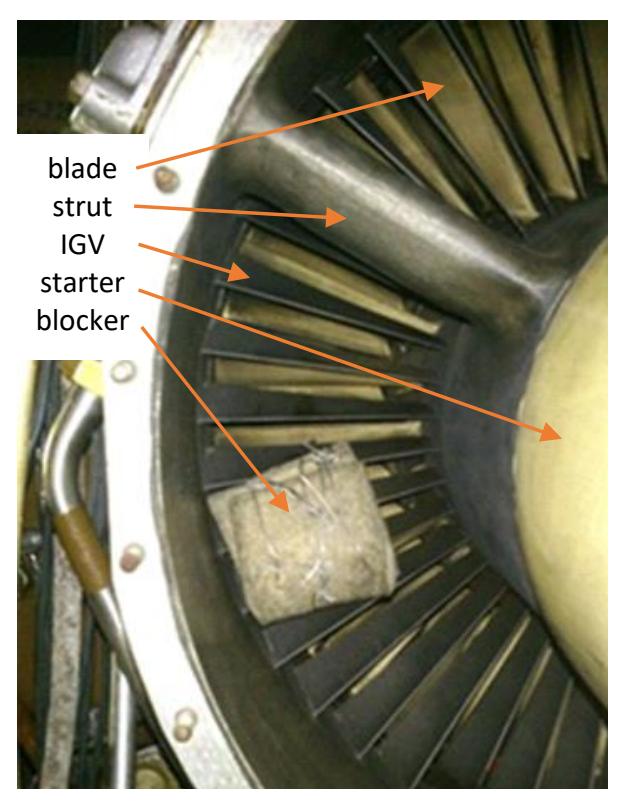

Figure 2. Felt blocker fixed in the inlet during the second test.

Two datasets (Figure 3) are analysed below:

1. Without inlet excitation (S001)

2. With the inlet blocker fitted (S349)

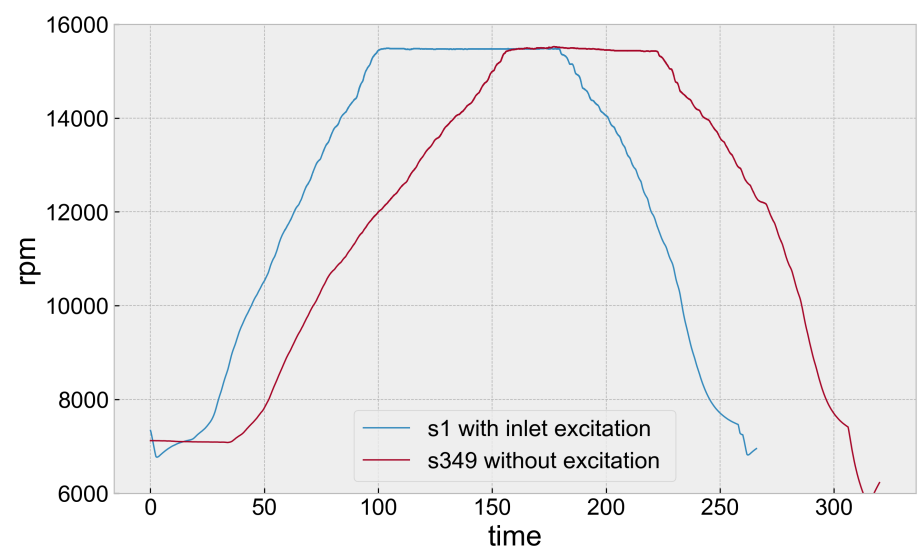

Figure 3. Speed profiles.

\subsection{Measurement Setup}

The acquired data included signals from eight variable reluctance probes installed in the first stage of the compressor and the once-per-revolution sensor, organised in the form of 'shots' comprising slow manoeuvres of increasing and decreasing rotational speed. The inductive probes, developed 
by ITWL, were placed at the following circumferential positions (Figure 4): 0.0, 19.7, 83.9, 93.4, 103.1, $113.1,122.7$, and 132.7 degrees in the slots machined under a previous project. For that reason, sensor spacing could not be optimised.

The data acquisition system was based on National Instruments PXI-1065 computer running a LabView application and two PXIe-6358 modules, which amplified and sampled sensor signals with the rate of $500 \mathrm{kHz}$. Waveforms were processed in real time by software edge detectors with linear interpolation so the resolution of blade arrival measurement (TOA) is not limited by the sampling rate [28]. The methodology of data acquisition and handling is described in more detail in paper [29].

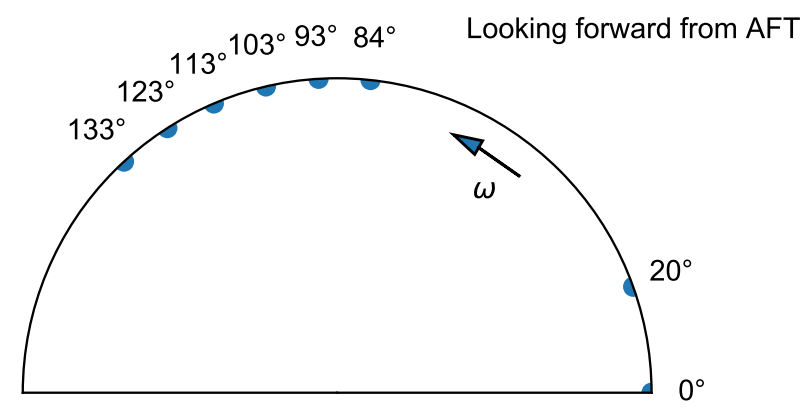

Figure 4. Positions of blade tip-timing (BTT) probes.

\subsection{Model}

The blade displacement $d_{j}$, measured at an individual blade for a given probe $j$ is of the following form:

$$
\begin{aligned}
d_{j}=P_{j}+a_{0} & +a_{1} \sin E O \theta_{j}+a_{2} \cos E O \theta_{j} \\
& +b_{1} \operatorname{sinfeo\theta } \theta_{j}+b_{2} \cos f e o \theta_{j}
\end{aligned}
$$

where $P_{j}$ is an invariant displacement offset for probe $j$ and is typically due to mechanical variation in the blade positions due to manufacturing tolerances and errors in probe positioning. $\theta_{j}$ is the angular position of probe $j$; EO is an integer engine order for synchronous vibration; $a_{0}$ is a non-probe specific, steady (i.e., non-vibrational) blade displacement offset due to aerodynamic loading and axial position [30], $a_{1}$ and $a_{2}$ are constants from which synchronous vibration amplitude and phase can be calculated; $f e o$ is a non-integral (fractional) engine order for asynchronous vibration; and $b_{1}$ and $b_{2}$ are constants from which asynchronous vibration amplitude and phase can be calculated.

For synchronous vibration, Equation (1) can be expressed in the following matrix form:

$$
\mathbf{d}=\mathbf{M a}
$$

where $\mathbf{d}=\left[\begin{array}{lll}d_{1} & . . & d_{M}\end{array}\right]^{T}, \mathbf{a}=\left[\begin{array}{lll}a_{0} & a_{1} & a_{2}\end{array}\right]^{T}, M$ - number of probes

$$
\mathbf{M}=\left|\begin{array}{ccc}
1 & \sin E O \theta_{1} & \cos E O \theta_{1} \\
1 . & \\
1 & \sin E O \theta_{M} & \cos E O \theta_{M}
\end{array}\right|
$$

The system was overdetermined because the number of probes $M$ was higher then the number of the vibration parameters $\mathbf{a}$, so the method of least squares can be applied to approximate the solution:

$$
\hat{\mathbf{a}}=\left(\mathbf{M}^{T} \mathbf{M}\right)^{-1} \mathbf{M}^{T} \mathbf{d} .
$$

The algorithms for solving the numerical problem are described by Jousselin et al. [7,22] and Russhard and Back [31]. The operation may be performed in a general-purpose package such as Matlab [10] or Python [29]. 
The obtained vector â is substituted to Equation (2) to compare the calculated displacements $\hat{\mathbf{d}}$ with the measured ones $\mathbf{d}$. It is more convenient to use correlation between $\mathbf{d}$ and $\hat{\mathbf{d}}$ to evaluate the goodness of fit instead of the residual $\mathbf{d}-\hat{\mathbf{d}}$. The correlation coefficient $r$ is calculated using the Pearson formula:

$$
r=\frac{\sum(d-\bar{d})(\hat{d}-\overline{\hat{d}})}{\sqrt{\sum(d-\bar{d})^{2}(\hat{d}-\overline{\hat{d}})^{2}}}
$$

This parameter ranges from 0 to 1 and is called 'coherence' below.

1Estimated vibration amplitude equals:

$$
\hat{A}=\sqrt{\hat{a}_{1}^{2}+\hat{a}_{2}^{2}}
$$

Traditionally, peak-to-peak amplitude is usually produced by tip timing systems for comparison with deflection charts:

$$
\hat{A}_{\mathrm{pk}-\mathrm{pk}}=2 \hat{A}=2 \sqrt{\hat{a}_{1}^{2}+\hat{a}_{2}^{2}}
$$

\subsection{Stack Pattern}

From Equation (1) it can be seen that for a blade undergoing no vibration, its steady state displacement is equal to $P_{j}$. For an ideal rotor with equally spaced blades, the value for each blade would be identical. In reality, the difference in manufacturing tolerances produces a pattern of displacements, which are the differences from the ideal position. It is unique for each rotor and shown as the stack plot [7]. It is calculated for each probe $j$ by averaging blade displacements over many revolutions:

$$
P_{i j}=\frac{1}{H} \sum_{h=1}^{H} d_{h i j}
$$

where $h$ is the revolution number, $i$-the blade number, $H$-the number of revolutions.

Changes in the stack pattern occur if (a) the blades undergo vibration [32] or (b) if the rotor is permanently damaged for some reasons. The stack plot is used to verify that the collected data sets are aligned correctly and is often applied as the first level of data validation. The analysis of misaligned data is a common fault in BTT data analysis.

\subsection{Software}

Blade deflection signals include undesirable components, such as noise, a static offset, a linear trend, and also some asynchronous vibration, which is not of interest. Conventional processing of BTT data relies upon preliminary operations such as alignment to ensure all data comes from the same rotation number, zeroing to isolate $P_{j}$ and filtering to isolate the integral response from the non-integral response [33].

In practice, the number of resonances, blades, and probes to analyse is sufficiently large that pre-processing and resonance fitting must be automated. The automation of analysis was achieved by Rolls Royce, which developed their Batch Processor software [34], which was released several years ago. The solver separates the integral and non-integral components of the blade displacement and uses a form of least squares fitting to generate the results for integral and non-integral responses. Where integral and non-integral displacements precede and follow on an integral response, or occur simultaneously, then that software fails.

In this work, a new solver called EMTD Multitool [35] was used. It has the ability to operate conventionally or by using alternative methods of pre-processing the data, which can be manipulated into the form:

$$
d_{j}=a_{0}+a_{1} \sin E O \theta_{j}+a_{2} \cos E O \theta_{j}
$$

where the value of $\mathrm{EO}$ is real number rather than an integer. 


\subsection{Uncertainty Measurement}

BTT uncertainties can be divided into three categories: those inherent in the physical act of taking the measurement, the pre-processing of the acquired data including the conversion to deflection and frequency, and finally, the challenge of converting the obtained deflections into blade stress [36]. The current capability of BTT for use in a compressor stress survey can, if all of the above uncertainties are addressed and controlled, produce end-to-end stress measurement with uncertainties of $\pm 2.5 \%$ or better. More importantly, a figure of uncertainty can now be calculated for every BTT measurement.

Typically, BTT responses are characterised by the quality of the least squares fitting. However, measurement uncertainty is often not known and the decision on whether the results are 'good' is subject to opinion. The calculation of the uncertainty value removes this doubt and provides upper and lower values to any BTT measurement.

The MultiTool solver calculates the measurement uncertainty for any point on the tracked order response. To do this, the least squares model is extended to contain a term that 'captures' any data that do not correlate with the engine order term. The uncertainty term includes the average and standard deviation of the non-related terms. From this, the measurement uncertainty is calculated over a pre-determined number of revolutions. The form of $u n c$ is not disclosed in this paper for commercial reasons.

$$
d_{j}=a_{0}+u n c+a_{1} \sin E O \theta_{j}+a_{2} \cos E O \theta_{j}
$$

\subsection{Data Analysis}

Integral responses were initially identified in the graph of the filtered blade displacement signal, coming from a selected sensor (Figure 5). Circumferential least squares fitting was applied to the observed vibration events. The engine orders to be fitted in the selected speed ranges were defined not only thanks to past experience, but also FEM modelling [37,38], prediction of likely vibrational modes and spectral analysis.

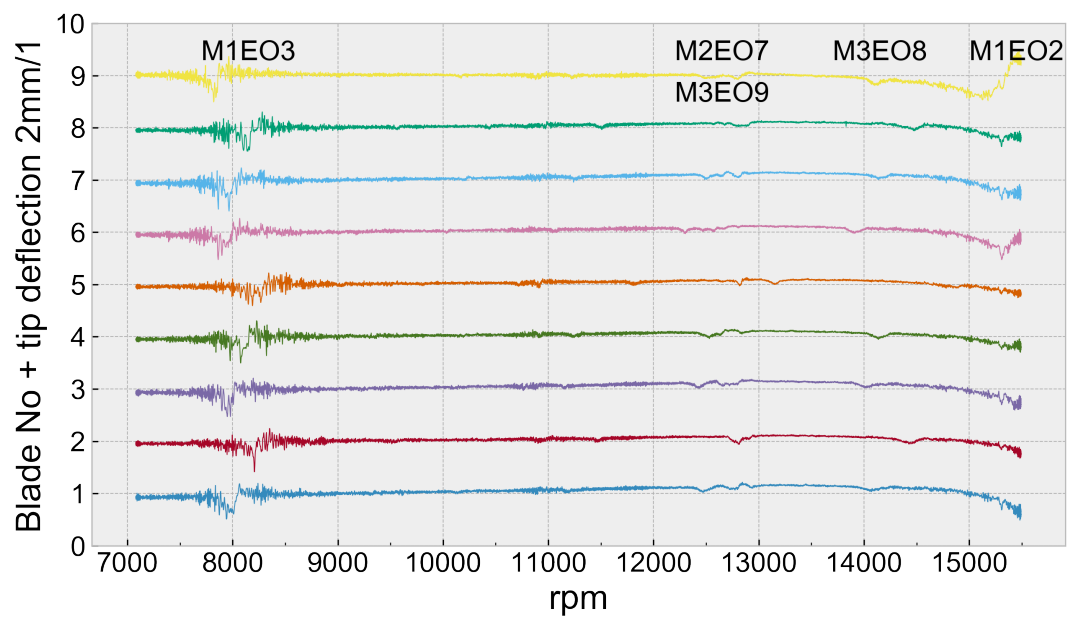

Figure 5. Tip deflection measured by sensor one as a function of rotational speed after low pass filtering (S349).

The approximate values of vibration frequency for selected modes and speeds were taken from the results of numerical modal analysis [39]. On the basis of this data, a Campbell diagram was plotted, which was necessary to set up the solver (Figure 6). The observed resonances M1EO2, M1EO3, M2EO7 and M2EO8 were fitted in the so-called 'synchronous analysis' with the integral engine order. The selection of resonances is limited by the available speed range (7200-15,500 rpm) and the set of engine orders which is generated by the excitation force. 
It can be seen that the M1EO2 and M2EO6 resonances (15,500 rpm) and also M2EO7 and M3EO9 $(12,500 \mathrm{rpm})$ were close together, so they may have required a double analysis, i.e., a model with two degrees of freedom. In the case of two simultaneous responses, a further term was added to the blade tmodel:

$$
\begin{aligned}
d_{j}=a_{0} & +a_{1} \sin E O_{1} \theta_{j}+a_{2} \cos E O_{1} \theta_{j} \\
& +a_{3} \sin E O_{2} \theta_{j}+a_{4} \cos E O_{2} \theta_{j}
\end{aligned}
$$

It is worth noting that the resonances M1EO3 and M2EO8 coincided with asynchronous vibrations occurring below 12,000 rpm. It could affect the estimation using the conventional solvers as they allow for fitting the selection with fixed orders only.

To analyse coinciding integral and non-integral vibrations, an alternative solver was employed which tracked the modal frequency in the band defined by the Campbell diagram, both in a steady state and transient mode. Fourier spectrum delivered the initial EO value for the measured displacements which was used for least square fitting regardless the type of the response. The engine order was then refined and the process repeated until satisfactory coherence was achieved.

The solver produced the sequence of amplitude and phase values estimated for subsequent revolutions, stored in spreadsheet files. The further sections deal with the processing of fitting results and interpreting them.

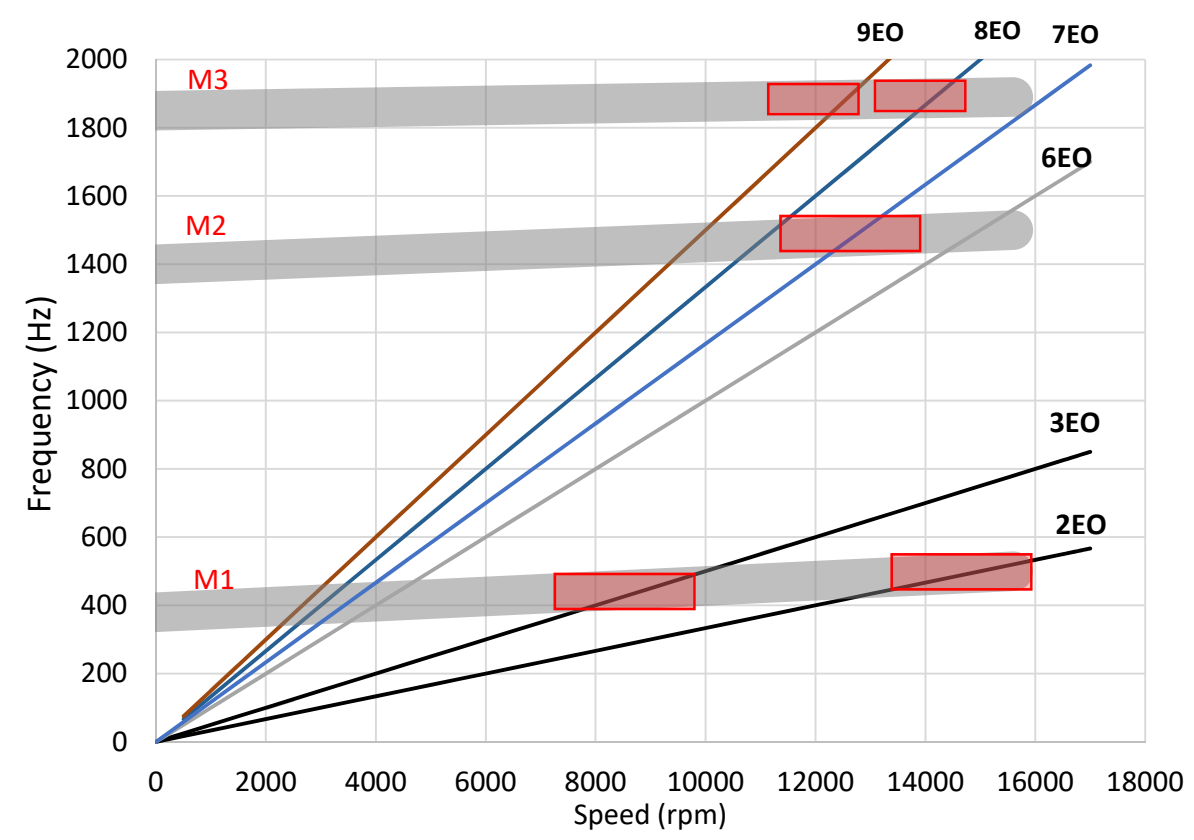

Figure 6. Campbell diagram: lines of synchronous excitation (spokes), predicted zones of vibratory modes M1-M3 and expected resonances.

\section{Results}

\subsection{EO2 Forced Response}

The SO-3 turbojet had a low order resonance in take-off range which is an obvious design error. It was observed that the inlet blocker doubled the amplitude of M1EO2 and other responses occurring above 12,000 rpm. The deflection curve at the take-off speed 15,500 rpm showed the blade leaning as it went towards resonance (Figure 5).

The stack pattern of the BTT data sets was used as a first level validation of the data. If carefully managed, it could be used as real time indicator of integral vibration reinforcing the dangers of looking 
at raw displacement curves to the untrained operator. In the case there are discrepancies, the analysis software should refuse to load incorrect data.

For s349 data-set, the extreme forced vibration reaching $3 \mathrm{~mm}$ pp distorted the stack plot (Figure 7). The mean values calculated for the stack deviated as a result of high integral vibration and consequently, the alignment checks on the stack pattern failed. Batch processor reported the stack pattern's error and denied loading and analysing the shot S349. There was no standard approach for cases when automated zeroing failed. Some software packages, including MultiTool, allow the data to be corrected for errors before allowing analysis. Both programs are unable to process this resonance properly without careful configuration requiring an understanding of BTT methods.
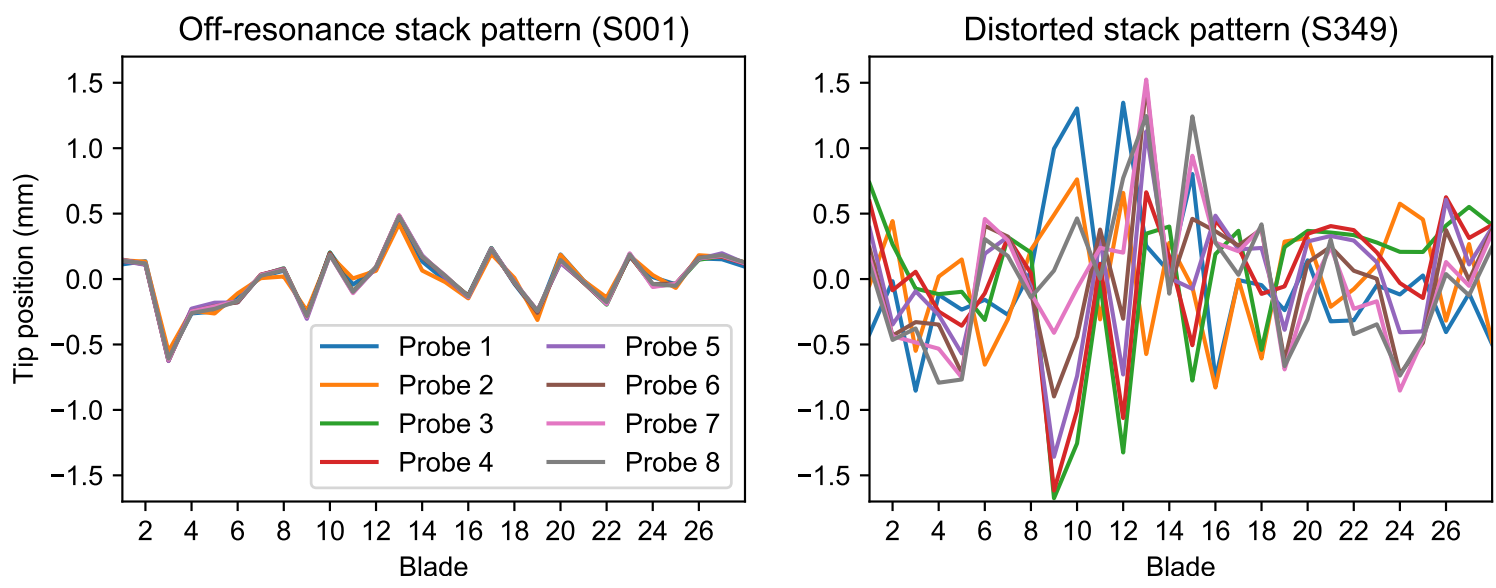

Figure 7. Stack plots.

The fitting results of the amplitude and phase of individual blades are available in spreadsheet files for further processing. Figure 8 shows the tracked order overlay for a single blade with and without the blocker. The same maximum speed was not reached for both setups, but a forced response was observed on the blade prior to approaching its resonant speed, as well as increased instability caused by the blocker. However, the resonance was not achieved in both cases due to speed limitations.

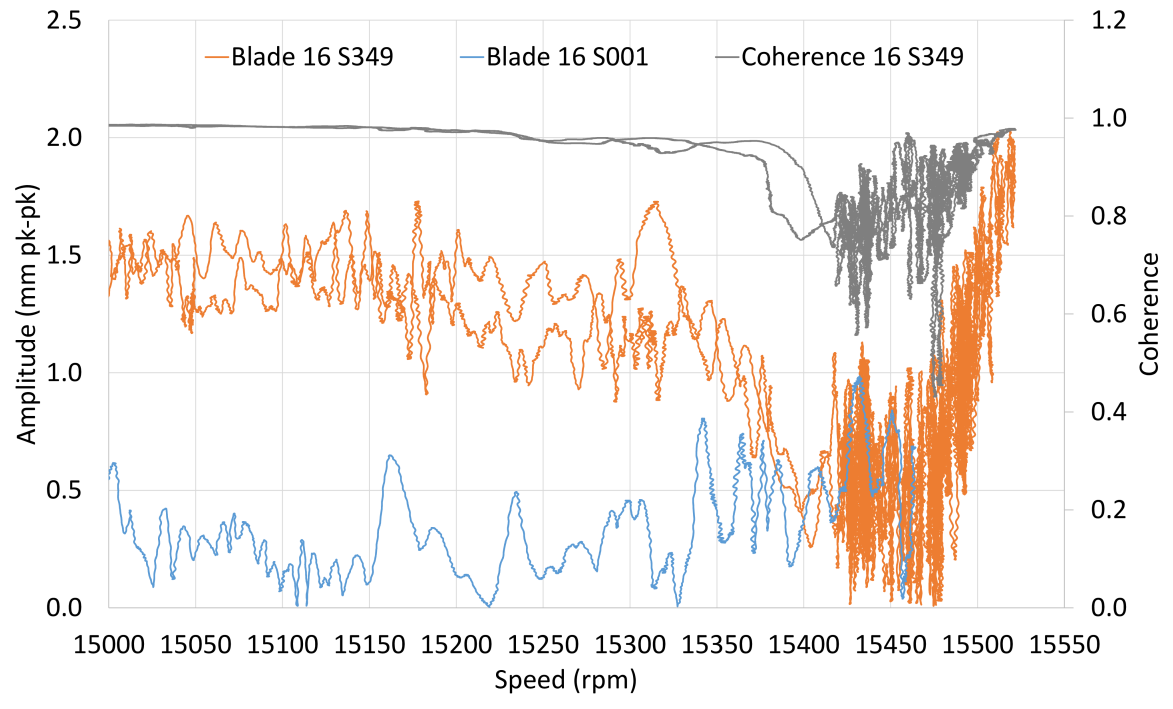

Figure 8. M1EO2 tracked order for a single blade.

The summary plot (Figure 9) shows that several high-responding blades were present, for which the M1EO2 resonance was very close. Ease in exciting them to excessive vibration posed a threat to the engine's durability. However, the mistuning pattern was very similar for the both tests (Figure 9) 
which confirmed that the blades were still healthy. The amplitude mistuning pattern can be applied to monitor blade health, similarly to the frequency one [40].

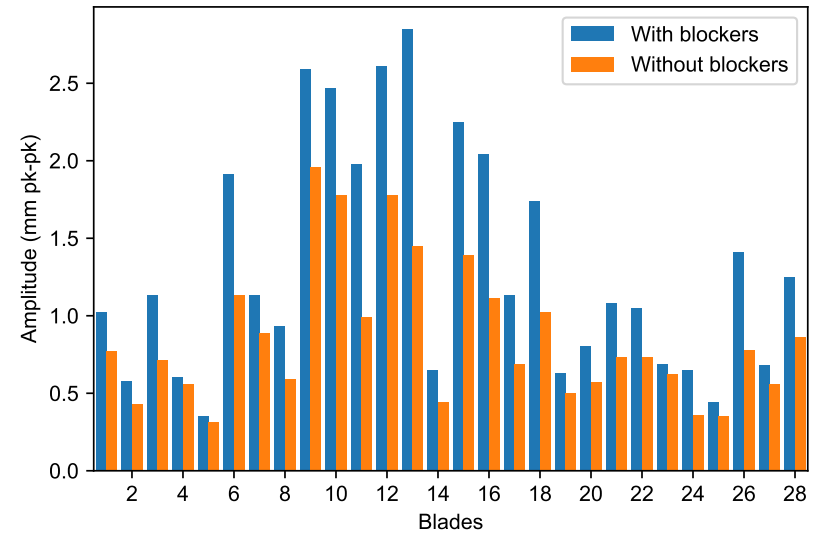

Figure 9. M1EO2 peak amplitude response for all blades.

As discussed by Heath and Imregun [41], fitting results indicate that the real tip deflection is ten percent greater than the peak amplitude of zigzag read from the single sensor chart (Figure 5). This kind of a coarse measurement, known as Zablotskiy method [42], should, therefore, be used only as a first approximation, while reliable synchronous vibration measurement requires a multi-sensor system. This is extremely important as viewing displacement plots for blades provides very little information but is often considered by engineers as an essential tool e.g., [3,43,44].

\subsection{Frequency Estimation}

In theory, vibration phase changes the sign when crossing the resonance but a 180-degree phase shift is observed in rare cases and cannot be used reliably to confirm the location of resonances. In a real test environment, examining each phase response visually is impractical even for low-order responses, which need many revolutions to sweep. If the phase shift was used as the only indicator defining the resonance, then less than $1 \%$ of existing resonances would be found in real engine datasets.

Mostly, it is assumed that the blade resonant frequency occurs at the point where amplitude reaches a maximum value. The quality factor of metal blades is high (e.g., 200 or more) so the resonance peak is a good approximation of the resonant frequency. The frequency measurements presented in the next section are obtained in this way. Unfortunately, the M1EO2 resonance was located in the vicinity of the upper-speed limit. As a result, no phase transition by zero was observed for the majority of blades, which means that the resonant frequency was not achieved, so it could not be reliably determined. Therefore, the values presented in Figure 9 correspond to the maximum amplitude reached by the solver.

In the case when full resonance is not achieved, erroneous results can be produced, although this is the same as with strain gauges. For M1EO2, checking the phase shift helps to avoid presenting false frequencies. In other cases, it is usually not necessary and could remove potentially good data, if the threshold is increased over 105 degrees.

Here, there was no simple method of measuring the resonant frequency of the blades whose $\mathrm{M} 1 \mathrm{EO} 2$ resonance was located beyond the maximum speed. The solution is to increase the maximum engine speed but it reduces engine durability and is not recommended for safety reasons.

\subsection{Higher Order Resonances}

The increase in amplitude caused by the blocker was also observed for the M1EO3 crossing at $8000 \mathrm{rpm}$ (Figure 10). The tracked order blade response showed the increase and decay of the amplitude. The resonance was traversed during the engine manoeuvre, so the blade response frequencies can be compared (Figure 11). The uncertainty of the presented resonant amplitudes was limited to $5 \%$ and 
is around $1 \%$ for the majority of blades. Therefore, error bars are not displayed in summary plots to avoid blurring them.

The blade amplitudes of the other resonances predicted by the Campbell diagram can be also extracted. It was apparent that integral M2 and M3 vibrations responded well only when the blocker was installed (shot s349). Figure 12a shows M2EO7 observed at 12,800 rpm which may be coincident with M3EO9, thus it was calculated as a double response. Similarly, the results from the double analysis for M3EO9 are shown in Figure 12b. This method involved factorisation of a larger matrix and thus took significantly more time than the single analysis.

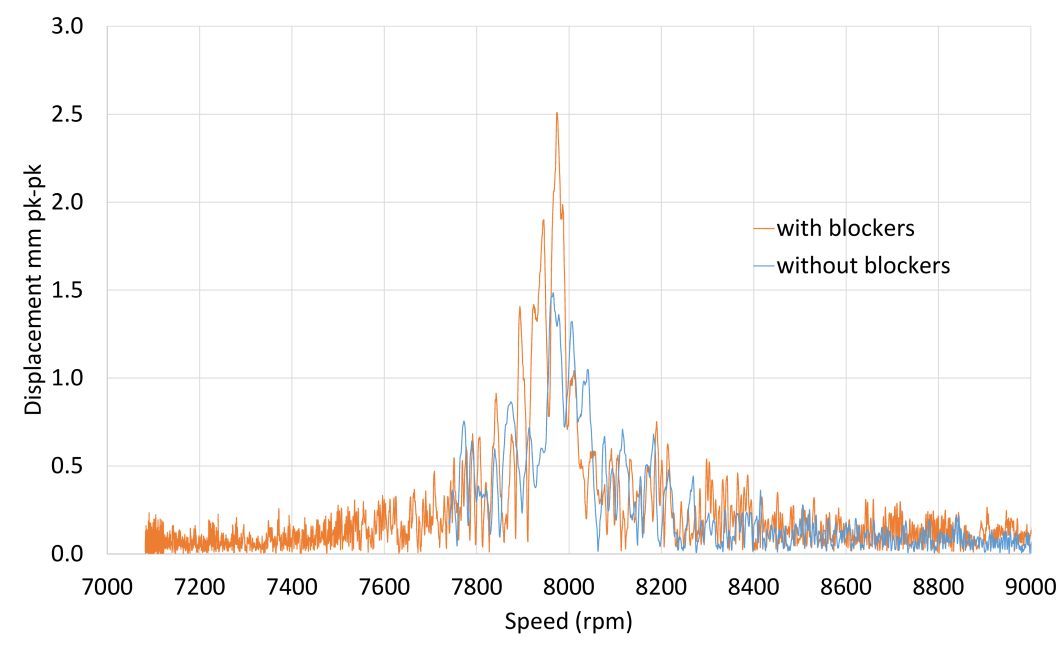

Figure 10. Single blade response-M1EO3.

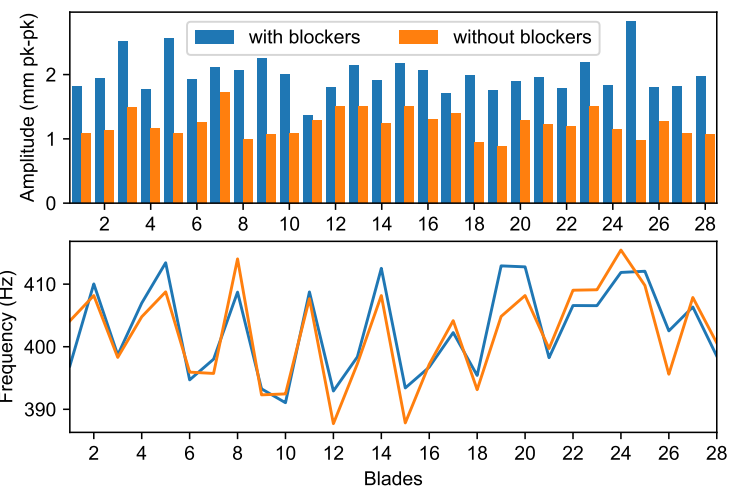

Figure 11. M1EO3 peak amplitudes and frequencies for all blades.

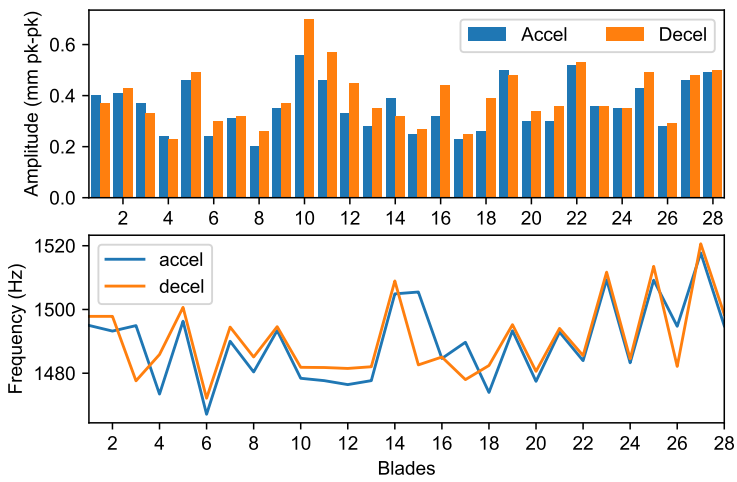

(a) M2EO7 amplitude and frequency

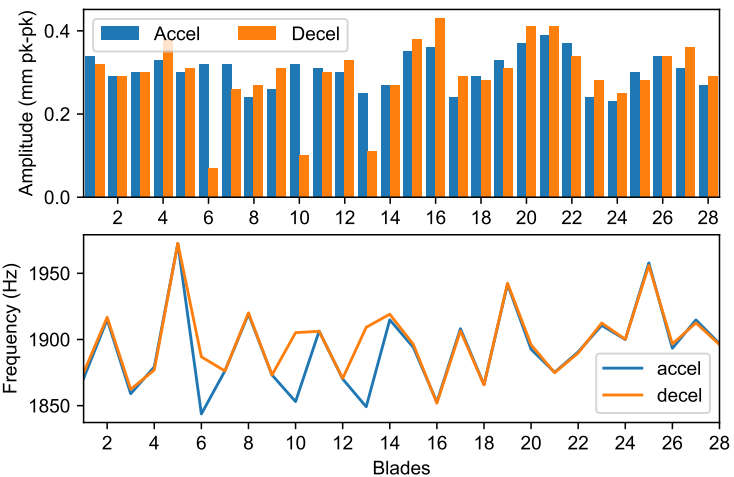

(b) M3EO9 amplitude and frequency

Figure 12. Double analysis. 
Observing the responses and overlaying them on a common speed time base (Figure 13) indicates that the two modes were not really coupled and could have been analysed as single responses.

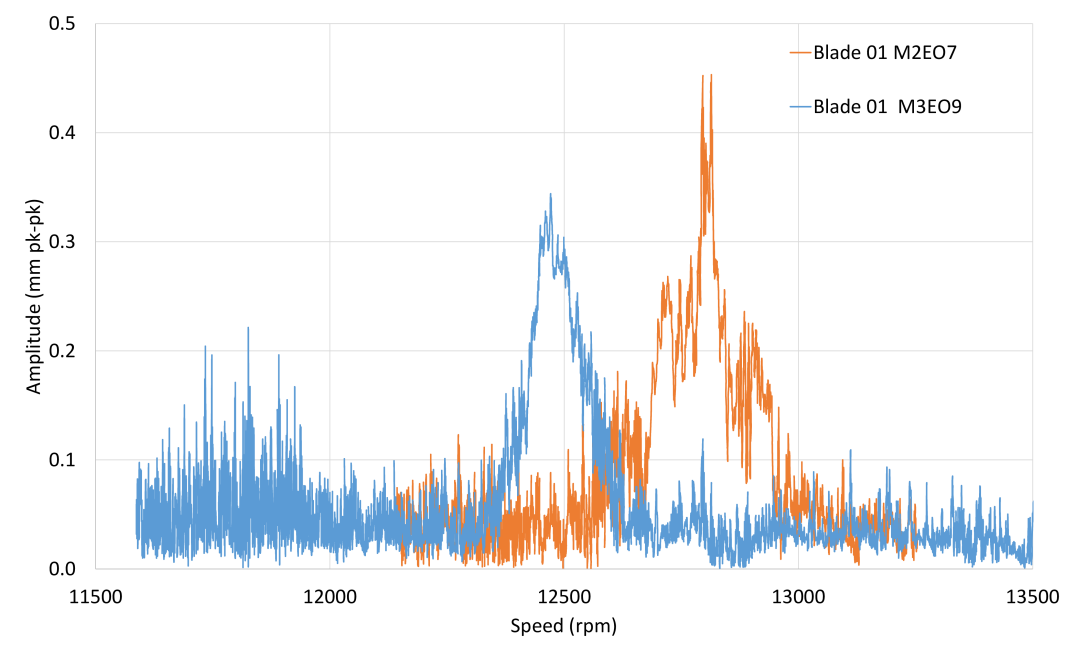

Figure 13. M2 and M3 overlay shows no coupling.

At about 14,000 rpm, another M3 resonance was observed (M3EO8), which was analysed as a single response and gave similar results as M3EO9 (Figure 14). A weak response from blade 5 for acceleration was masked by the use of a coherence and uncertainty filter. Measurement uncertainty can be used to assess the overall results because it is calculated for any point on the tracked order response (Figure 15).

Lowering the thresholds for the filters would then reveal the amplitude for blade 5. However, its uncertainties would be outside of the limits set by the user. In reality, it indicates that a clean response from this blade cannot be obtained and for this particular manoeuvre can be ignored.

The mistuning patterns presented in this section, both amplitude and frequency, are intended to be used for monitoring blade health. BTT methods provide data from many blades unlike the strain gauges, so it is acceptable to ignore 'noisy responses'. However, in the case where the blade is always unable to produce the expected response, a more detail post-test inspection of the blade would be pertinent.

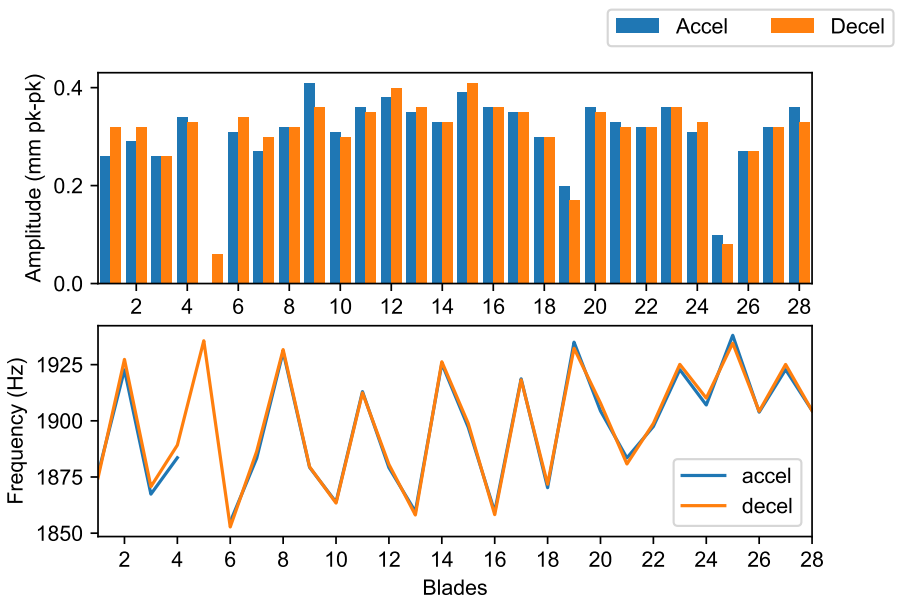

Figure 14. M3EO8 amplitude and frequency. 


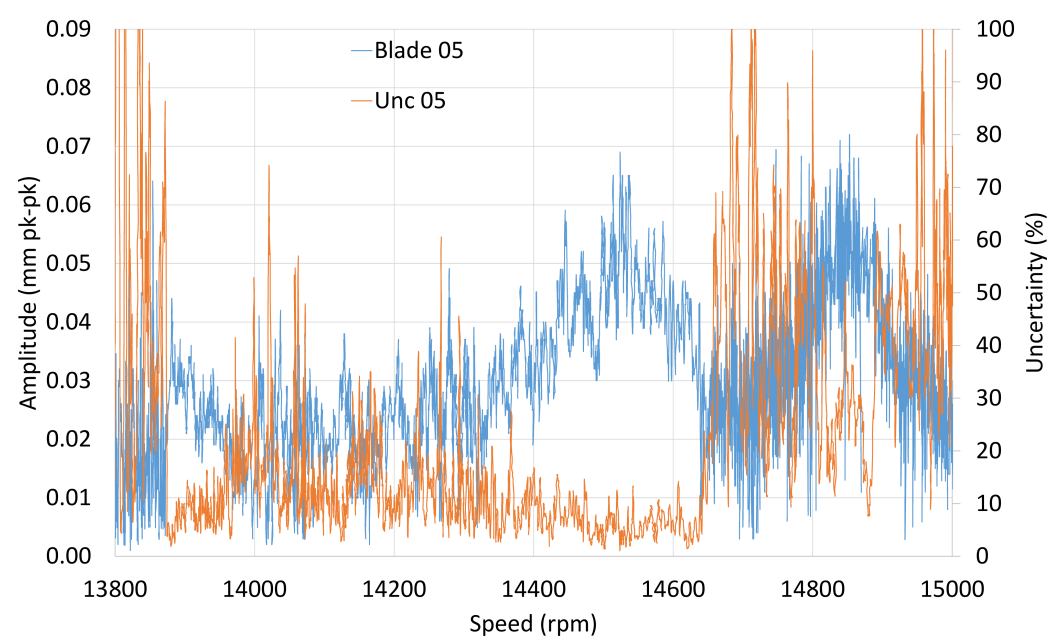

Figure 15. M3EO8 amplitude uncertainty.

Responses of higher modes than M3 and orders greater than nine, despite being predicted by FEM modelling, did not respond sufficiently for most of the blades to meet required fit quality and uncertainty levels. A more selective excitation method such as oil jets or electromagnets is necessary to investigate them. Probe positioning has to be redesigned to cover high orders and complex mode shapes. Limited spatial resolution of the inductive sensor could be a barrier [45]. Another problem with higher orders is that they last only for a few revolutions, so an accurate FEM model and more precise speed control are needed to find them.

\subsection{Asynchronous Vibration}

The compressor is not equipped with guided vanes, so there are rotating stall and other intensive asynchronous vibrations observed below 12,000 rpm that disappear at higher speeds. This is shown in the all-blade spectrum plotted for the s1 dataset (Figure 16).

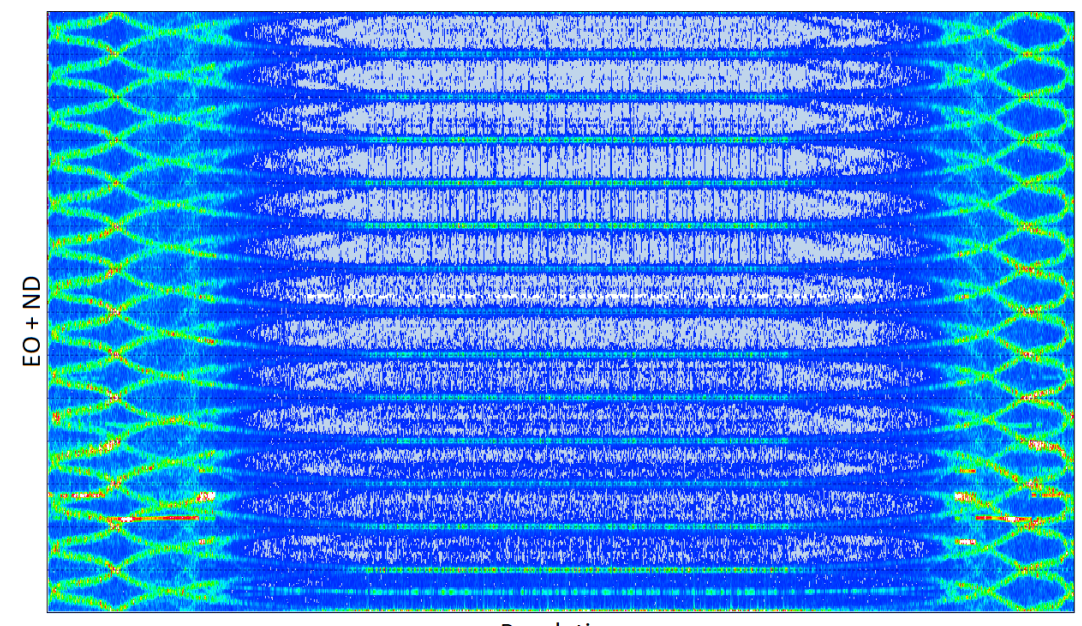

Revolutions

Figure 16. Travelling wave plot.

When the speed changes (the left and right part of Figure 16), vibrations of individual blades are visible in the spectrum in the form of a crossing of the engine order axis of the diagram. Asynchronous vibration is presented as a coherent trace over the blue background denoting the noise floor. The 
average assembly amplitude and nodal diameter of travelling wave responses can be found by observing the vibration from two different angular positions [46-48]:

$$
N D=\frac{\phi_{2}-\phi_{1}}{\theta_{2}-\theta_{1}}
$$

$\phi_{j}$ is the phase of the spectral line observed by probe $j$. Figure 17 shows a zoomed region showing a rotating stall response, which arises during ramp-up at the idle speed and exists up to 11,500 rpm. This is M1 vibration with the nodal diameter -4 ND and 1.8 EO.

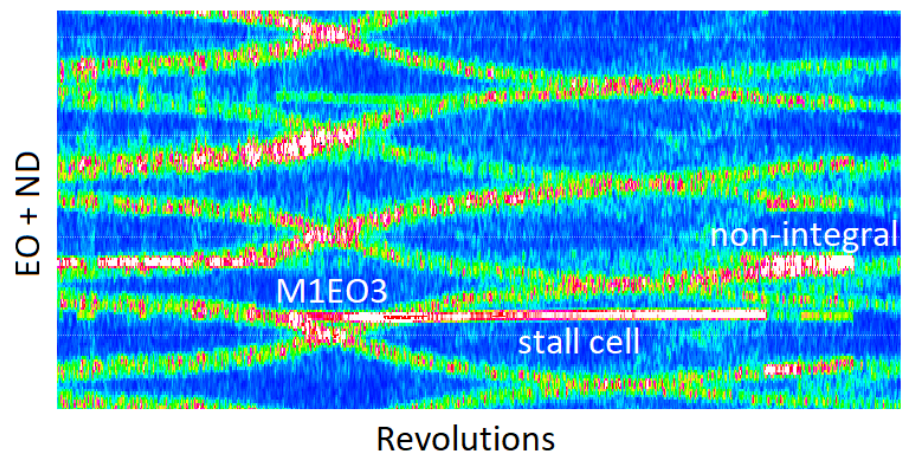

Figure 17. Zoomed travelling wave plot.

The data produced so far has used the conventional pre-processing methods of separating both the integral and non-integral terms through a filtering and zeroing process and then performing least squares fitting that is seeded with the estimated response engine orders. If the conventional integral solver is applied to the region shown in Figure 17, only the peak response at the resonance can be extracted. The software is not able to change the order on the fly so the fitting fails for speeds higher than 8500 rpm (Figure 18a).

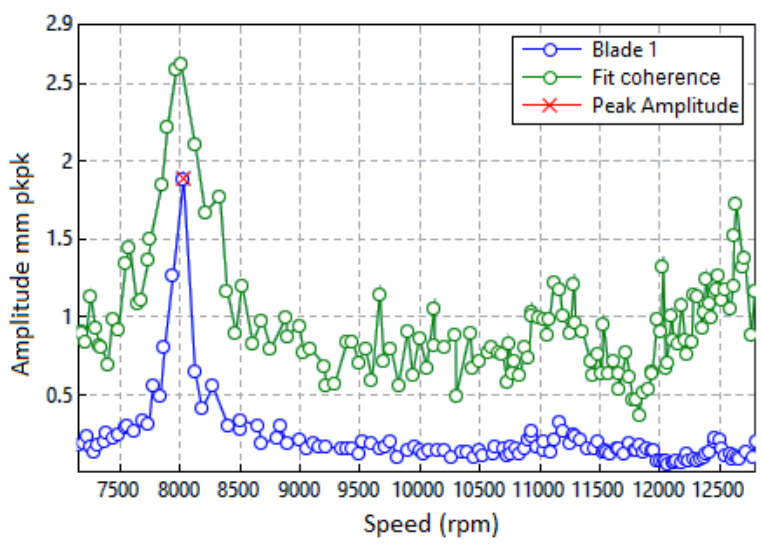

(a) Integral response-conventional solver

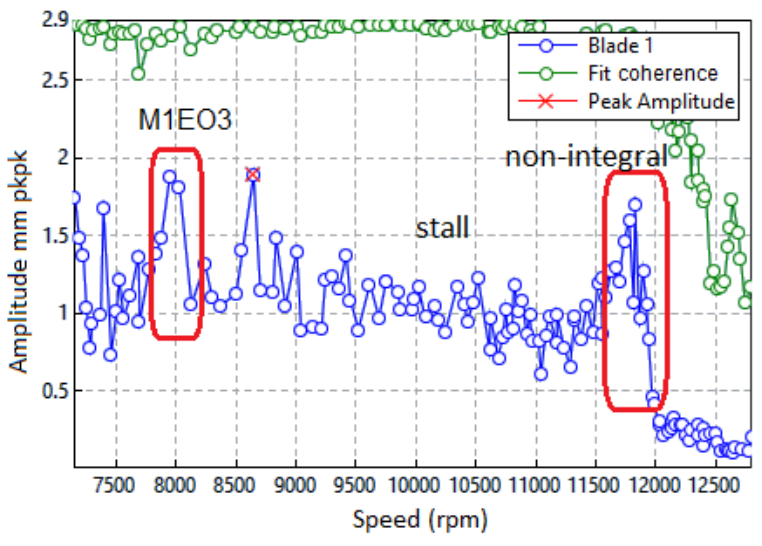

(b) Stall region analysed by mode tracking

Figure 18. Conventional solver vs. mode tracking.

By using alternate methods to process and fit the data, the simpler model (Equation (9)) can be applied irrespective of the type of vibration. It delivers the mode tracked response similar to that which is produced from strain gauges. When applied to the region of interest, the modal solver reveals the peak amplitude which occurred in the stall for some blades and that the stall collapsed at 12,000 rpm (Figure 18b). For the three successive responses observed in the region i.e., the M1EO3 resonance, stall cell and natural M1 non-integral response, the peak amplitudes of individual blades are obtained (Figure 19b). Both methods i.e., the traditional fixed-order LSF and proposed modal solver, give similar 
results for homogeneous responses. The differences can be attributed to the pre-processing filtering and zeroing techniques used.

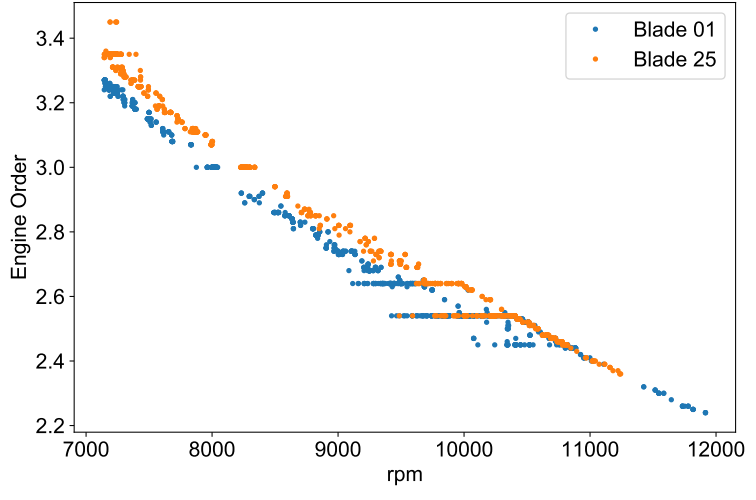

(a) Engine order

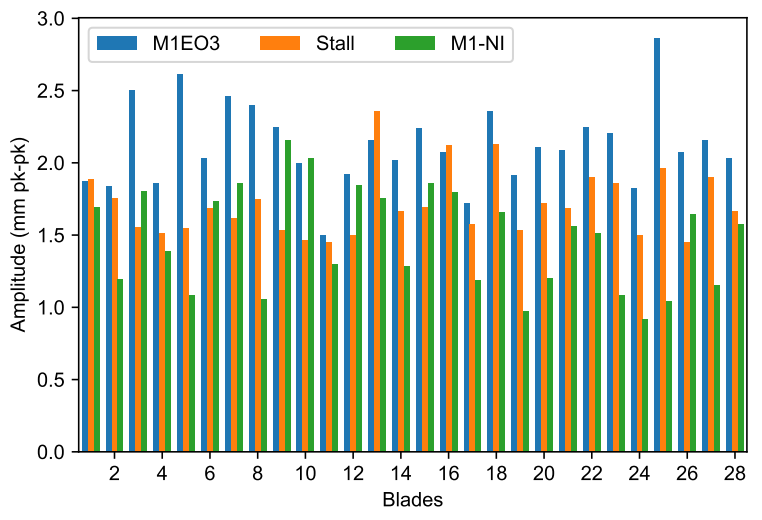

(b) Amplitude

Figure 19. Successive M1 responses analysed using modal tracking solver.

\section{Discussion}

Vibration analysis is necessary for designing compressors and turbines in a way that reduces the risk of high-cycle fatigue of the material, which under certain conditions can lead to cracking and breaking of the blades. Knowing the real dynamic properties of the blades is crucial both for designers and users of gas turbines. In this example, it is shown that complex modes of vibration such as simultaneous resonances and travelling wave responses can occur in any compressor, even in a legacy turbojet of a basic structure.

The problem of the excessive vibration of SO-3 fan blades in the take-off range is well understood and $\mathrm{M} 1 \mathrm{EO} 2$ responses are visible on the tip-deflection traces without any additional measures. Even for such a basic response, reading deflection charts is imprecise and largely affected by the human factor. Only model-based vibration analysis can be used when developing and certifying components.

The BTT method has its limitations and can only partially replace the strain gauges [9]. For example, it is difficult to measure higher modes of vibrations, whose deflections in the direction of rotation are of a few microns. If they are accompanied by significant stresses, they can be observed with strain gauges, but there are also problems with transmitting the signals of several kilohertz frequencies by the telemetry system and the effect of the strain gauge on high-frequency responses.

Observing coinciding responses with the non-intrusive method requires a good understanding of dynamics based on FEM models and proper preparation of the analysis. Higher-order modes can be measured providing that sensors with a suitable spatial resolution are used, the circumferential and axial distribution of the sensors is optimised and the method of exciting vibrations is effective. Many responses which are numerically predicted are extremely difficult to be excited in a test cell. They can be observed only in compressor rigs or vacuum spin facilities equipped with sophisticated excitation systems.

Using the maximum value of the resonance curve gives a good approximation of the resonant frequency. In a few cases, it can be determined based on the speed, at which the vibration phase passes through zero. The obtained frequency charts show that the blades are ordered by their natural frequency during assembly to ensure the differences in the neighbourhood of $\pm 2 \%$. Despite the high mistuning, a travelling wave response was observed with an average assembly amplitude of around $1.5 \mathrm{~mm} \mathrm{pp}$, which was part of the rotating stall occurring due to the lack of variable guided vanes.

\section{Conclusions}

The recent version of least squares analysis, handling non-integral engine orders, is an effective method of estimating synchronous and non-synchronous vibrations that can cope with real signals 
including noise. The presented solver can track the modal frequency and adjust the engine order on the fly. The obtained results are constantly evaluated by monitoring coherence and uncertainty. This procedure let us analyse the three close M1 responses (integral, stall and non-integral) in one go and saved a lot of the tedious work configuring the conventional solver, in which the integer and non-integer responses are treated separately. By using the same method for both types of vibration, it was possible to examine the interaction between the rotating stall and the M1EO3 resonance. This generalised approach to blade vibration analysis and uncertainty estimation is an important step towards replacing strain gauges in engine certification.

Author Contributions: Conceptualization, R.P.; methodology, R.P. and P.R.; formal analysis, R.P. and P.R.; software, R.P. and P.R.; validation, R.P. and P.R.; investigation, R.P.; resources, R.P.; writing-original draft preparation, R.P.; writing - review and editing, R.P. and P.R.; visualization R.P. and P.R. All authors have read and agreed to the published version of the manuscript.

Funding: This publication includes the results of the project financed by the Polish National Science Centre (NCN) under the decision DEC-2011/01/D/ST8/07612 and the research task of the statutory activity of ITWL 'Demonstrator of the system to measure turbine blade vibration', financed by the Ministry of Science and Higher Education in 2018-2019.

Acknowledgments: We would like to thank Michał Wachłaczenko and Wojciech Sujka for their involvement in the project and support for engine tests.

Conflicts of Interest: The authors declare no conflict of interest.

\section{Abbreviations}

The following symbols and abbreviations are used in this manuscript:

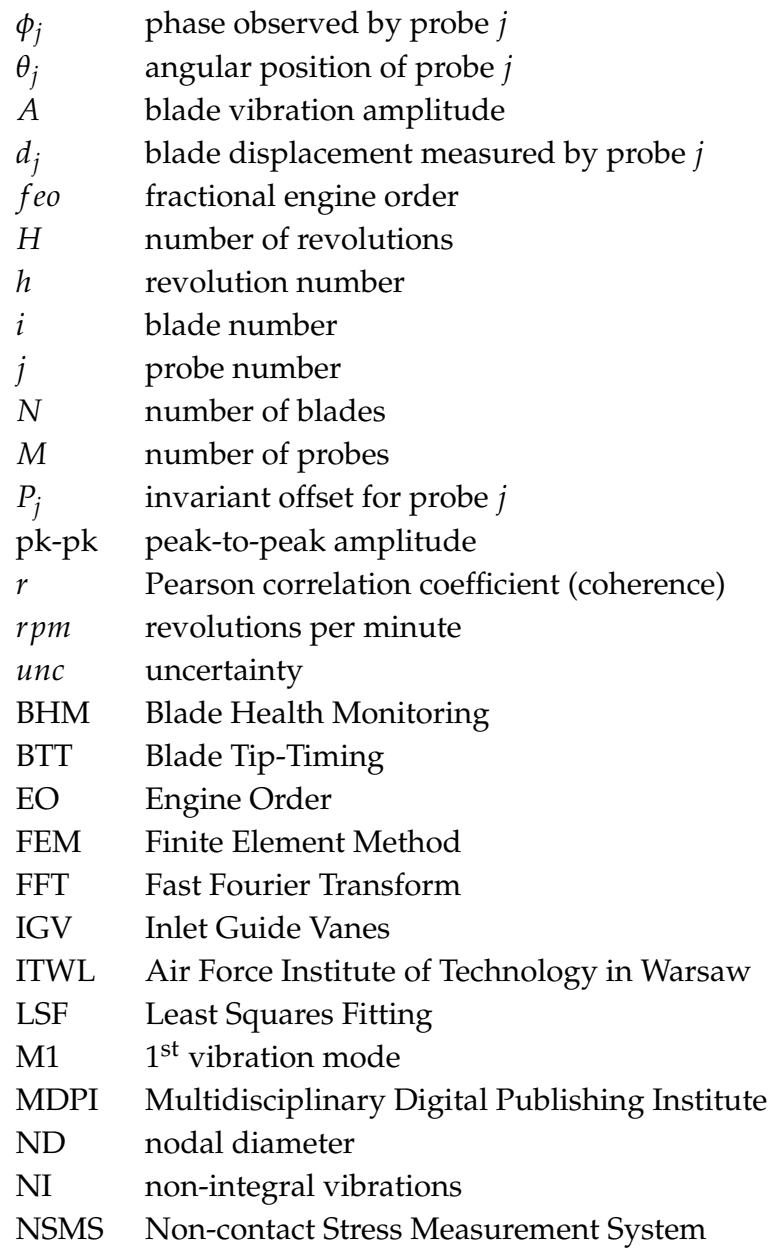




\section{References}

1. Russhard, P. The Rise and Fall of the Rotor Blade Strain Gauge. In Vibration Engineering and Technology of Machinery; Mechanisms and Machine Science; Sinha, J.K., Ed.; Springer International Publishing: Cham, Switzerland, 2015; Volume 23, pp. 27-38. [CrossRef]

2. Mevissen, F.; Meo, M. A Review of NDT/Structural Health Monitoring Techniques for Hot Gas Components in Gas Turbines. Sensors 2019, 19, 711. [CrossRef]

3. Zhao, X.; Zhou, Q.; Yang, S.; Li, H. Rotating Stall Induced Non-Synchronous Blade. Sensors 2019, $19,4995$. [CrossRef]

4. Ye, D.; Duan, F.; Jiang, J.; Cheng, Z.; Niu, G.; Shan, P.; Zhang, J. Synchronous vibration measurements for shrouded blades based on fiber optical sensors with lenses in a steam turbine. Sensors 2019, $19,2501$. [CrossRef]

5. Agilis Non-Intrusive Stress Measurement Systems Fundamentals; Technical Report; Agilis Measurement Systems: Palm Beach Gardens, FL, USA, 2014.

6. Tappert, P.; Losh, D. Analyze Blade Vibration 6.1 User Manual; Technical Report; Hood Technology Corporation: Hood River, OR, USA, 2007.

7. Jousselin, O. Development of Blade Tip Timing Techniques in Turbo Machinery. Ph.D. Thesis, The University of Manchester, Manchester, UK, 2013.

8. Russhard, P. Analysis of Rotating Stall in a Contra-Rotating System using Blade Tip Timing. In Proceedings of the 58th International Instrumentation Symposium, San Diego, CA, USA, 4-8 June 2012; pp. 1-33.

9. Knappett, D.; Garcia, J. Blade tip timing and strain gauge correlation on compressor blades. Proc. Inst. Mech. Eng. Part G J. Aerosp. Eng. 2008, 222, 497-506. [CrossRef]

10. Przysowa, R. The Analysis Of Synchronous Blade Vibration Using Linear Sine Fitting. J. Konbin 2014, 30, 5-19. [CrossRef]

11. Dimitriadis, G.; Carrington, I.; Wright, J.; Cooper, J. Blade-Tip Timing measurement of Synchronous Vibrations of Rotating Blade assemblies. Mech. Syst. Signal Process. 2002, 16, 599-622. [CrossRef]

12. Beauseroy, P.; Lengellé, R. Nonintrusive turbomachine blade vibration measurement system. Mech. Syst. Signal Process. 2007, 21, 1717-1738. [CrossRef]

13. Teolis, C.; Teolis, A.; Paduano, J.; Lackner, M. Analytic representation of eddy current sensor data for fault diagnostics. In Proceedings of the 2005 IEEE Aerospace Conference, Big Sky, MT, USA, 5-12 March 2005; pp. 1-11. [CrossRef]

14. Li, M.; Duan, F.; Ouyang, T. Analysis of blade vibration frequencies from blade tip timing data. Proc. SPIE 2010, 7544, 7544-7544F. [CrossRef]

15. Diamond, D.H.; Heyns, P.S.; Oberholster, A.J. A Comparison Between Three Blade Tip Timing Algorithms for Estimating Synchronous Turbomachine Blade Vibration. In Proceedings of the 9th WCEAM 2014 World Congress on Engineering Asset Management; Lecture Notes in Mechanical Engineering; Amadi-Echendu, J., Hoohlo, C., Mathew, J., Eds.; Springer International Publishing: Cham, Switzerland, 2015; Volume 20, pp. 215-225. [CrossRef]

16. Kharyton, V.; Dimitriadis, G.; Defise, C. A Discussion on the Advancement of Blade Tip Timing Data Processing. In Proceedings of the ASME Turbo Expo 2017: Turbomachinery Technical Conference and Exposition, Charlotte, NC, USA, 26-30 June 2017. [CrossRef]

17. Bastami, A.R.; Safarpour, P.; Mikaeily, A.; Mohammadi, M. Identification of Asynchronous Blade Vibration Parameters by Linear Regression of Blade Tip Timing Data. J. Eng. Gas Turbines Power 2018, 140, 072506. [CrossRef]

18. Zhang, J.W.; Zhang, L.B.; Duan, L.X. A Blade Defect Diagnosis Method by Fusing Blade Tip Timing and Tip Clearance Information. Sensors 2018, 18, 2166. [CrossRef] [PubMed]

19. Hu, Z.; Lin, J.; Chen, Z.S.; Yang, Y.M.; Li, X.J. A non-uniformly under-sampled blade tip-timing signal reconstruction method for blade vibration monitoring. Sensors 2015, 15, 2419-2437. [CrossRef] [PubMed]

20. Chen, Z.; Liu, J.; Zhan, C.; He, J.; Wang, W. Reconstructed order analysis-based vibration monitoring under variable rotation speed by using multiple blade tip-timing sensors. Sensors 2018, 18, 3235. [CrossRef] [PubMed] 
21. Pan, M.; Yang, Y.; Guan, F.; Hu, H.; Xu, H. Sparse Representation Based Frequency Detection and Uncertainty Reduction in Blade Tip Timing Measurement for Multi-Mode Blade Vibration Monitoring. Sensors 2017, 17, 1745. [CrossRef]

22. Jousselin, O.; Russhard, P.; Bonello, P. A method for establishing the uncertainty levels for aero-engine blade tip amplitudes extracted from blade tip timing data. In Proceedings of the 10th International Conference on Vibrations in Rotating Machinery, London, UK, 11-13 September 2012; pp. 211-220.[CrossRef]

23. Courtney, S. A Robust Process for the Certification of Rotating Components Using Blade Tip Timing Measurements z. In Proceedings of the ISA 57th IIS 2nd Tip Timing Workshop; The International Society of Automation: St. Louis, MO, USA, 2011.

24. Drewczynski, M.; Rzadkowski, R.; Ostrowska, Z. Dynamic Stress Analysis of a Blade in a Partially Blocked Engine Inlet. In Proceedings of the ASME Turbo Expo 2014: Turbine Technical Conference and Exposition. Volume 7B: Structures and Dynamics, Düsseldorf, Germany, 16-20 June 2014.[CrossRef]

25. Morris, R.; Littles, J.W.; Hall, B.; Owen, W.D.; Tulpule, S.; Szczepanik, R.; Przysowa, R. Crack Detection and Prognosis Using Non-Contact Time of Arrival Sensors for Fan and Compressor Airfoils In Gas Turbine Engines. In Proceedings of the 20th Advanced Aerospace Materials and Processes (AeroMat) Conference and Exposition; ASM International: Dayton, OH, USA, 2009; pp. 1-26.

26. Witoś, M. High sensitive methods for health monitoring of compressor blades and fatigue detection. Sci. World J. 2013, 2013. [CrossRef] [PubMed]

27. Szczepanik, R. Experimental Investigations of Aircraft Engine Rotor Blade Dynamics; Wydawnictwo Instytutu Technicznego Wojsk Lotniczych: Warsaw, Poland, 2013.

28. Przysowa, R.; Kaźmierczak, K. Triggering methods in blade tip-timing systems. In Proceedings of the Twelve International Conference on Vibration Engineering and Technology of Machinery, VETOMAC XII; Rządkowski, R., Szczepanik, R., Eds.; Instytut Techniczny Wojsk Lotniczych: Warsaw, Poland, 2016; pp. 129-138. [CrossRef]

29. Przysowa, R.; Tuzik, A. Data Management Techniques for Blade Vibration Analysis. J. Konbin 2016, 37, 95-132. [CrossRef]

30. Mohamed, M.; Bonello, P.; Russhard, P. A Novel Method for the Determination of The Change in Blade Tip Timing Probe Sensing Position Due to Steady Movements. Mech. Syst. Signal Process. 2019, 126, 686-710. [CrossRef]

31. Russhard, P.; Back, J.D. Rotating Blade Analysis. U.S. Patent 9,016,132, 28 April 2015.

32. Ye, D.; Duan, F.; Jiang, J.; Niu, G.; Liu, Z.; Li, F. Identification of vibration events in rotating blades using a fiber optical tip timing sensor. Sensors 2019, 19, 1482. [CrossRef]

33. Russhard, P. BTT Data Zeroing Techniques. In Proceedings of the 59th International Instrumentation Symposium and 2013 MFPT Conference; The International Society of Automation: Cleveland, OH, USA, 2013; pp. 1-46.

34. Jousselin, O. Blade Tip Timing Batch Processor User Guide DNS147027; Technical Report; Rolls-Royce plc: Derby, UK, 2010.

35. Russhard, P. MultiTool Blade Tip Timing Acquisition, Analysis and Data Simulation Software; EM0102-Analysis Manual; Technical Report; EMTD Ltd.: Nottingham, UK, 2016.

36. Russhard, P. Blade tip timing (BTT) uncertainties. AIP Conf. Proc. 2016, 1740, 020003. [CrossRef]

37. Sinha, S.K.; Turner, K.E. Natural frequencies of a pre-twisted blade in a centrifugal force field. J. Sound Vib. 2011, 330, 2655-2681. [CrossRef]

38. Chakshu, N.K.; Sinha, S.K. Natural Frequencies of Pre-Twisted Airfoil Blades. In Proceedings of the ASME 2017 Gas Turbine India Conference. Volume 2: Structures and Dynamics; Renewable Energy (Solar, Wind); Inlets and Exhausts; Emerging Technologies (Hybrid Electric Propulsion, UAV, ...); GT Operation and Maintenance; Materials and Manufacturing (Including Coatings, Composites, CMCs, Additive Manufacturing); Analytics and Digital Solutions for Gas Turbines/Rotating Machinery, Bangalore, India, 7-8 December 2017. [CrossRef]

39. Rzadkowski, R.; Szczepanik, R.; Drewczyński, M. Analiza dynamiczna łopatek wirnikowych i kierowniczych silnika jednoprzeptywowego (Dynamic analysis of turbojet's blades and vanes); ITWL: Warsaw, Poland, 2013. 
40. Russhard, P. The Use of Blade Tip Timing Technologies to Assess and Monitor Rotor Blade Health from Design to Production. In STO-MP-AVT-229_-Test Cell and Controls Instrumentation and EHM Technologies for Military Air, Land and Sea Turbine Engines; NATO Science and Technology Organization: Rzeszow, Poland, 2015; Chapter 11, pp. 1-27.

41. Heath, S.; Imregun, M. An improved single-parameter tip-timing method for turbomachinery blade vibration measurements using optical laser probes. Int. J. Mech. Sci. 1996, 38, 1047-1058. [CrossRef]

42. Zablotskiy, I.Y.; Korostelev, Y.A.; Sviblov, L.B. Contactless Measuring of Vibrations in the Rotor Blades of Turbines; FTD-HT-23-673-74; Lopatochnyye Mashiny i Struynyye Apparaty; Foreign Technology Div: Wright-Patterson AFB, OH, USA, 1972; pp. 106-121.

43. Zhang, J.; Duan, F.; Niu, G.; Jiang, J.; Li, J. A blade tip timing method based on a microwave sensor. Sensors 2017, 17, 1097. [CrossRef] [PubMed]

44. Gil-García, J.M.; Solís, A.; Aranguren, G.; Zubia, J. An architecture for On-Line measurement of the tip clearance and time of arrival of a bladed disk of an aircraft engine. Sensors 2017, 17, 2162. [CrossRef] [PubMed]

45. Russhard, P. A Comparison of Multi Fibre and Single Fibre Optical Probes. In Proceedings of the 60th International Instrumentation Symposium and IET Conference, London, UK, 24-26 June 2014; pp. 1-5. [CrossRef]

46. Watkins, W.B.; Chi, R.M. Noninterference blade-vibration measurement system for gas turbine engines. J. Propuls. Power 1989, 5, 727-730. [CrossRef]

47. Gill, J.D.; Capece, V.R.; Fost, R.B. Experimental methods applied in a study of stall flutter in an axial flow fan. Shock Vib. 2004, 11, 597-613. [CrossRef]

48. García, I.; Beloki, J.; Zubia, J.; Aldabaldetreku, G.; Asunción Illarramendi, M.; Jiménez, F. An optical fiber bundle sensor for tip clearance and tip timing measurements in a turbine rig. Sensors 2013, 13, 7385-7398. [CrossRef]

(C) 2019 by the authors. Licensee MDPI, Basel, Switzerland. This article is an open access article distributed under the terms and conditions of the Creative Commons Attribution (CC BY) license (http:/ / creativecommons.org/licenses/by/4.0/). 